\title{
Novel 3D embryo implantation model within macroporous alginate scaffolds
}

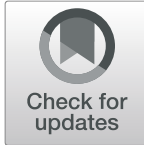

\author{
Dganit Stern-Tal ${ }^{1}$, Hanna Achache ${ }^{1}$, Liora Jacobs Catane ${ }^{1}$, Reuven Reich ${ }^{1 *}$ and Tali Tavor Re'em ${ }^{2^{*}}$ (D)
}

\begin{abstract}
Background: Implantation failure remains an unsolved obstacle in reproductive medicine. Previous studies have indicated that estrogen responsiveness, specifically by estrogen receptor alpha (ERa), is crucial for proper implantation. There is an utmost need for a reliable in vitro model that mimics the events in the uterine wall during the implantation process for studying the regulatory mechanisms governing the process. The current twodimensional and hydrogel-based in vitro models provide only short-term endometrial cell culture with partial functionality.

Results: Endometrial biopsies showed an increase in E-cadherin expression on the typical window of implantation of fertile women, compared to negligible expression in recurrent implantation failure (RIF) patients. These clinical results indicated E-cadherin as a marker for receptivity. Three-dimensional (3D) macroporous alginate scaffolds were the base for epithelial endometrial cell-seeding and long-term culture under hormone treatment that mimicked a typical menstrual cycle. The RL95-2 epithelial cell culture in macroporous scaffolds was viable for 3 weeks and showed increased E-cadherin levels in response to estrogen. Human choriocarcinoma (JAR) spheroids were used as embryo models, seeded onto cell constructs and successfully adhered to the RL95-2 cell culture. Moreover, a second model of HEC-1A with low ERa levels, showed lower E-cadherin expression and no JAR attachment. Ecadherin expression and JAR attachment were recovered in HEC-1A cells that were transfected with ERa plasmid.

Conclusions: We present a novel model that enables culturing endometrial cells on a 3D matrix for 3 weeks under hormonal treatment. It confirmed the importance of ERa function and E-cadherin for proper implantation. This platform may serve to elucidate the regulatory mechanisms controlling the implantation process, and for screening and evaluating potential novel therapeutic strategies for RIF.
\end{abstract}

Keywords: Embryo implantation, Alginate, Porous scaffold, Endometrium, Epithelial endometrial cells, Recurrent implantation failure, RIF, 3D in vitro model, Menstrual cycle, Hormone treatment

\section{Background}

Embryo implantation is considered relatively ineffective in humans $[1,2]$, as the probability of implantation is only $25 \%$ per menstrual cycle [3]. Implantation rates are even lower in women who suffer from recurrent implantation failures (RIF) after a number of in vitro

\footnotetext{
* Correspondence: reuvenr@ekmd.huji.ac.il; talire@jce.ac.il

${ }^{1}$ School of Pharmacy, Institute for Drug Research, The Hebrew University of Jerusalem, 91120 Jerusalem, Israel

${ }^{2}$ Department of Pharmaceutical Engineering, Azrieli College of Engineering Jerusalem, 26 Yaakov Shreibom Street, 9103501 Jerusalem, Israel
}

fertilization treatments [4]. It has been estimated that inadequate uterine receptivity is responsible for approximately two-thirds of the cases [5]. Previous studies have indicated that estrogen responsiveness, specifically by estrogen receptor alpha $(E R \alpha)$, is crucial for proper implantation [6]. Moreover, RIF patients have shown increased levels of Slug [4], an E-cadherin gene suppressor, relative to fertile women [6]. These studies suggest a positive correlation between ER $\alpha$ and E-cadherin and their role in the embryo implantation process. In this study, E-cadherin protein expression was assessed in RIF 
endometrium tissue and showed significantly lower protein levels relative to fertile women on day 21 , the typical window of implantation (WOI).

Further examination of the regulatory mechanisms governing the complex embryo implantation process requires an in vitro model for uterine functionality; particularly since human experiments are ethically impractical and animal in vivo models suffer from major dissimilarities regarding their reproductive physiology and implantation rates compared to human. Constructing such a model requires either human endometrial primary cells, derived from Pipelle ${ }^{\bullet}$ sampling, or modified endometrial cell lines such as RL95-2, HEC-1A, Ishikawa, etc., [7] along with an embryo-like model such as human choriocarcinoma (JAR) spheroids [7]. Furthermore, estrogen and progesterone are also required for the endometrial culture since they are key hormones that regulate the menstrual cycle and are involved in the implantation process [8].

To date, most of the current in vitro implantation studies have been conducted on monolayer, two dimensional (2D) culture systems [9-13]. 2D limitations were addressed by cell seeding onto different coated substrates, such as Matrigel $^{\circ}[14,15]$, and using advanced microfluidic systems [16]. However, 2D cell cultures, even when seeded onto thick gels, do not mimic the actual complex three-dimensional (3D) tissue, nor do they survive for more than a few days under hormonal treatment. Consequently, monolayer cultures cannot model the complex embryo implantation process, particularly the steps of apposition and invasion into the deeper layers of the endometrial tissue. To date, endometrial cells have been cultured in a number of 3D hydrogel systems, e.g., Matrigel $^{\circ}$ [17], collagen-Matrigel ${ }^{\circ}$ composites [18], fibrin-agarose [19, 20] and gelatin [21]. These 3D hydrogel culture systems support a variety of physiological processes, such as cell-cell and cell-matrix interactions, and expression of well-characterized cellular biomarkers, indicating that cells cultured in a $3 \mathrm{D}$ environment can represent in vivo cellular behavior [19]. These hydrogel systems were advantageous compared to monolayer cultures; however, they were characterized by relatively short cultivation periods (hours to days) due to limited access to medium and paracrine factors, both crucial to fully represent the temporally dynamic endometrium tissue. No current in vitro uterine model emulates the entire periodic behavior and tissue functionality in terms of temporal embryo attachment at a specific time - the WOI.

This study presents a porous scaffold as an alternative culture method for enabling 3-week long culture of epithelial cells under hormone treatment that mimics the typical menstrual cycle. Porous 3D matrices are beneficial for long-term cell culture, drug delivery and cell transplantation [22-28], due to high mass transfer efficiency and better exchange of nutrients, oxygen, waste, etc. [29]. Macroporous alginate scaffolds have been extensively used for long-term primary human cultures due to their high porosity and interconnected pore structure [22-25]. These scaffolds have been thoroughly characterized by Cohen and colleagues, e.g., scaffold porosity, pore architecture and compressibility [29,30], and cell viability, morphology and function [22, 24, 25, 31].

Macroporous alginate scaffolds were used for engineering endometrial models to mimic receptive vs. nonreceptive tissue, using appropriate human epithelial endometrial cell lines, RL95-2 and HEC-1A, respectively. We constructed a 3D in vitro endometrial culture that was grown for 3 weeks, the length of the menstrual cycle, under hormonal conditions that mimic in vivo conditions. This model functioned as a novel implantation model that allowed us to examine the roles of ER $\alpha$ and E-cadherin throughout the menstrual cycle. JAR spheroid attachment served as a model for embryo implantation and to examine potential therapeutic solutions for RIF patients.

\section{Results \\ E-cadherin expression in fertile women and in RIF patients}

E-cadherin immuno-staining of endometrium tissue from day 10 of the normal menstrual cycle of fertile women showed positive staining of E-cadherin in the epithelium (Fig. 1A and B). On day 21 of the menstrual cycle, the epithelium expressed E-cadherin (Fig. 1C), localized in the cell membrane of the epithelial cells (Fig. 1D). This membranal localization of E-cadherin was not observed on day 10 (Fig. 1B versus 1D), presumably due to its localization within the cytosol. Only very low expression of E-cadherin was detected in the endometrium tissue from RIF patients on day 21 of their normal menstrual cycle (Fig. 1E and F).

Western blot (WB) analysis of endometrial biopsies of fertile women revealed that E-cadherin protein expression increased from the proliferative phase on day 10 $(n=9)$ to the secretory phase on day $21(n=10)$ of the menstrual cycle (Fig. $1 \mathrm{G}$ and $\mathrm{H}, p<0.05$ ). Moreover, Ecadherin protein was either absent or hardly expressed in the secretory endometrium of RIF patients $(n=12$, Fig. $1 \mathrm{G}$ and $\mathrm{H}, p<0.05)$.

\section{Long-term endometrial cell viability in the 3D in vitro model}

Macroporous alginate scaffolds, fabricated by a freezedrying technique, had an internal structure of high porosity (>90\%) and interconnecting pores with an average pore size of $80.8 \mu \mathrm{m}$ and SD of $25 \mu \mathrm{m}$ (Fig. 2A), similar to previous studies [32], which enabled cell infiltration, 

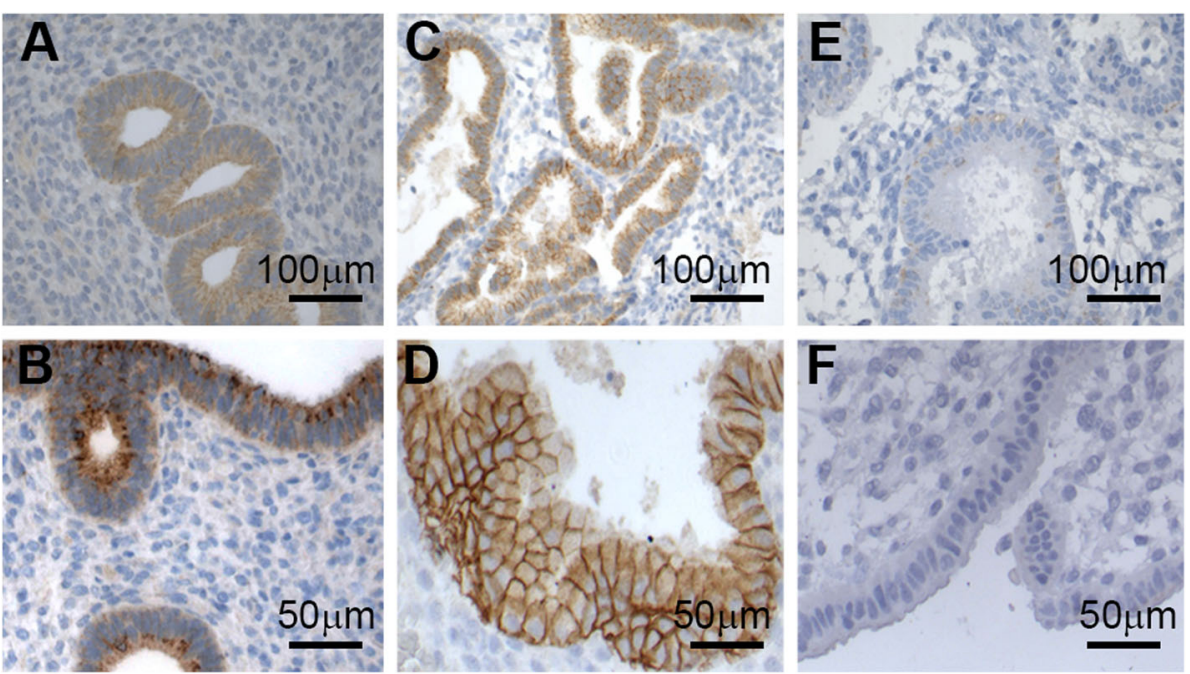

Fertile, Day 10

Fertile, Day 21

RIF, Day 21

G

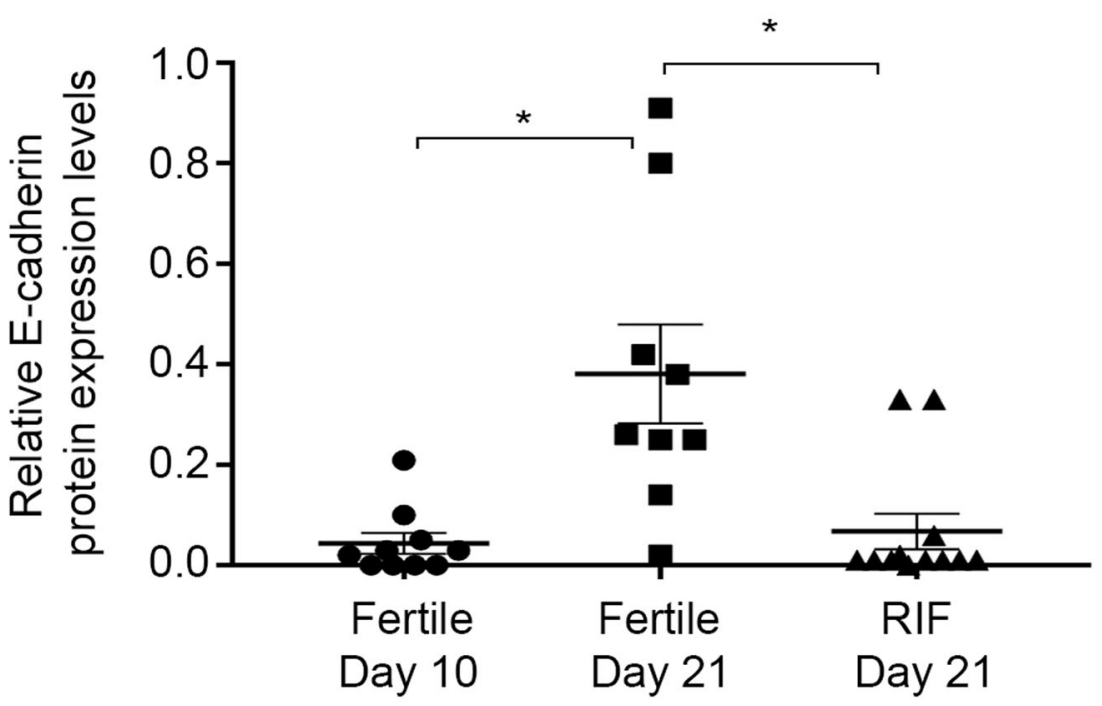

H

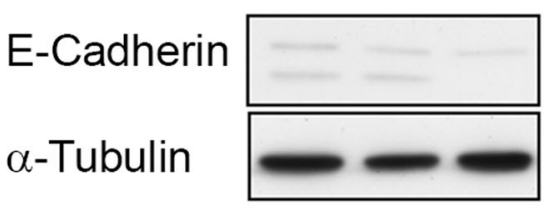

Fertile

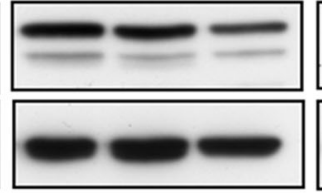

Fertile

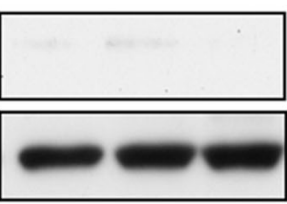

RIF

Fig. 1 A-F E-cadherin expression in the endometrium of fertile and RIF patients. Representative photomicrographs of E-cadherin immunostaining of paraffin sections of fertile female endometrium (A, B) on day 10, and (C, D) day 21 when E-cadherin was localized in the epithelial cell membrane. Almost no E-cadherin expression was detected in RIF patients' endometrial tissue on day 21 (E, F). (Bar: A, C, E: 100 m; B, D, F: $50 \mu \mathrm{m})$. G Quantification of E-cadherin protein expression levels by Western blot (WB) of endometrium from fertile women on day $10(n=9)$ and day 21 of the menstrual cycle $(n=10)$, and of RIF patients on day 21 of the cycle $(n=12, p<0.05,1$-way ANOVA, Dunnett's post-test). Expression levels were quantified by the band intensity relative to a-tubulin. $\mathbf{H}$ Representative E-cadherin WB 


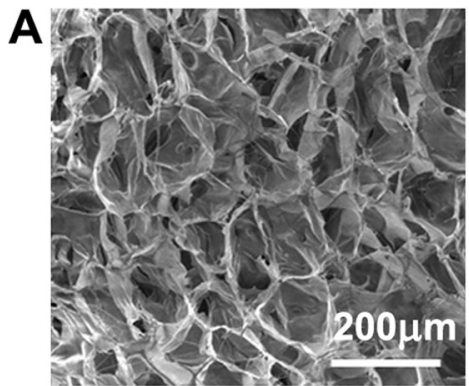

Scaffold

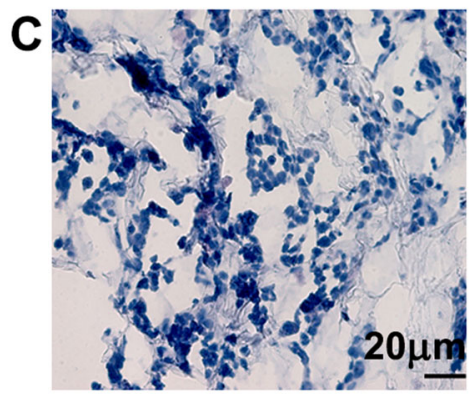

Week 2
B

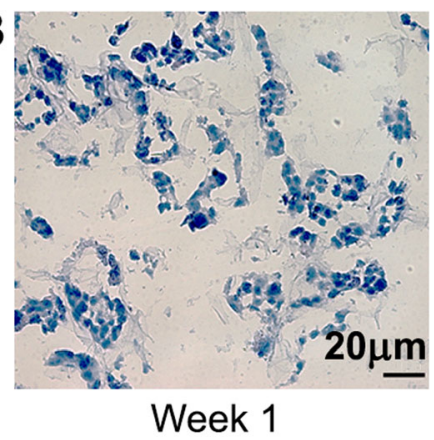

D

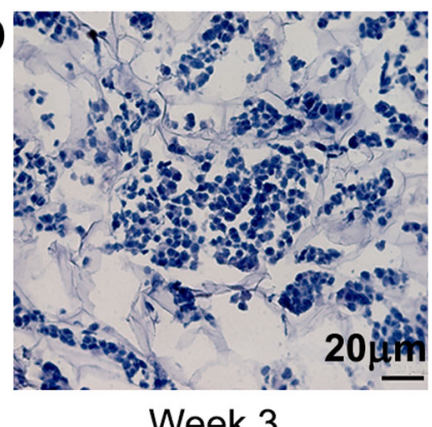

Fig. 2 Three-week culture of endometrial cells within macroporous alginate scaffolds. A Macroporous structure of alginate scaffold visualized by SEM (Bar: $200 \mu \mathrm{m})$. B-D H\&E staining of thin cryo-sections $(10 \mu \mathrm{m})$ of 3D endometrial RL95-2 cell constructs within macroporous alginate scaffolds after $\mathbf{B} 1$ week, C 2 weeks and D 3 weeks of cultivation (Bar: $20 \mu \mathrm{m}$ )

accommodation of a large number of cells, and good exposure to nutrients and hormonal treatment.

RL95-2 endometrial epithelial cells (hematoxylin and eosin (H\&E) stained) were nested within the interconnected pores of the scaffold; in Fig. 2B - D the infrastructure of the scaffold was evident in grey and no indication of fragmented nuclei was observed. Under static conditions, the cells resided at the surface of the scaffold enabling direct contact with the spheroids. Cell viability was confirmed by MTT tetrazolium salt assay that indicated cell viability for at least 4 weeks (data not shown) and Presto blue (PB) quantitative analysis (Supplementary Fig. 1).

\section{Hormonal response in the 3D model}

The mRNA expression levels of E-cadherin in the 3D RL95-2 endometrial model were elevated after 2 weeks of treatment with estrogen-containing medium, compared to hormone-free treatment, confirming model responsiveness to estrogen (Fig. 3A, $p<0.05$ ). Moreover, E-cadherin immunostaining indicated that protein expression was more pronounced after 2 (Fig. $3 \mathrm{Ba}$ ) and 3 (Fig. 3Bb) weeks of estrogen treatment compared to hormone-free treatment at the same time points (Fig. $3 \mathrm{BC}$ and $\mathrm{Bd}$, respectively); further indicating the responsiveness of the model to estrogen. Monolayer, 2D cultures of RL95-2 cells did not survive more than 3 days under hormonal treatment (data not shown).

\section{Adhesion of JAR in the RL95-2 3D model}

JAR cells within the spheroid exhibited compact cell morphology with enhanced cell-cell interactions and an overall dense spheroid structure with defined boundaries, as judged by H\&E staining (Fig. 4A). JAR spheroids successfully attached to the epithelial endometrial cells when co-cultured with RL95-2 cell constructs (Fig. 4B). The structure of the co-cultured-JAR spheroid was characterized by two areas, one with distinct boundaries, similar to the single spheroid (upper part of the spheroid, Fig. 4B), and the other at the interface between the spheroid and the epithelial cells underneath which showed attachment points (lower part of the spheroid, Fig. 4B, and at higher magnification, Fig. 4C). The epithelial cells were detected within the interconnected pores of the scaffold (Fig. 4D), as shown in Fig. 2B-D, and therefore were easily distinguishable from the JAR cells. The cellular interface between the RL95-2 cells and the JAR spheroids are shown in Fig. 4E. The adhesions of JAR spheroids were observed in all five of the five different RL95-2 cell constructs. Empty scaffolds were incubated with JAR spheroids under the same conditions and no spheroids were observed in any of the scaffolds (data not shown). Non-specific fluorescent membrane staining of RL95-2 cells with PKH67 (green) and JAR spheroids with PKH26 (red), followed by JAR seeding onto the RL95-2-seeded scaffold, confirmed the 

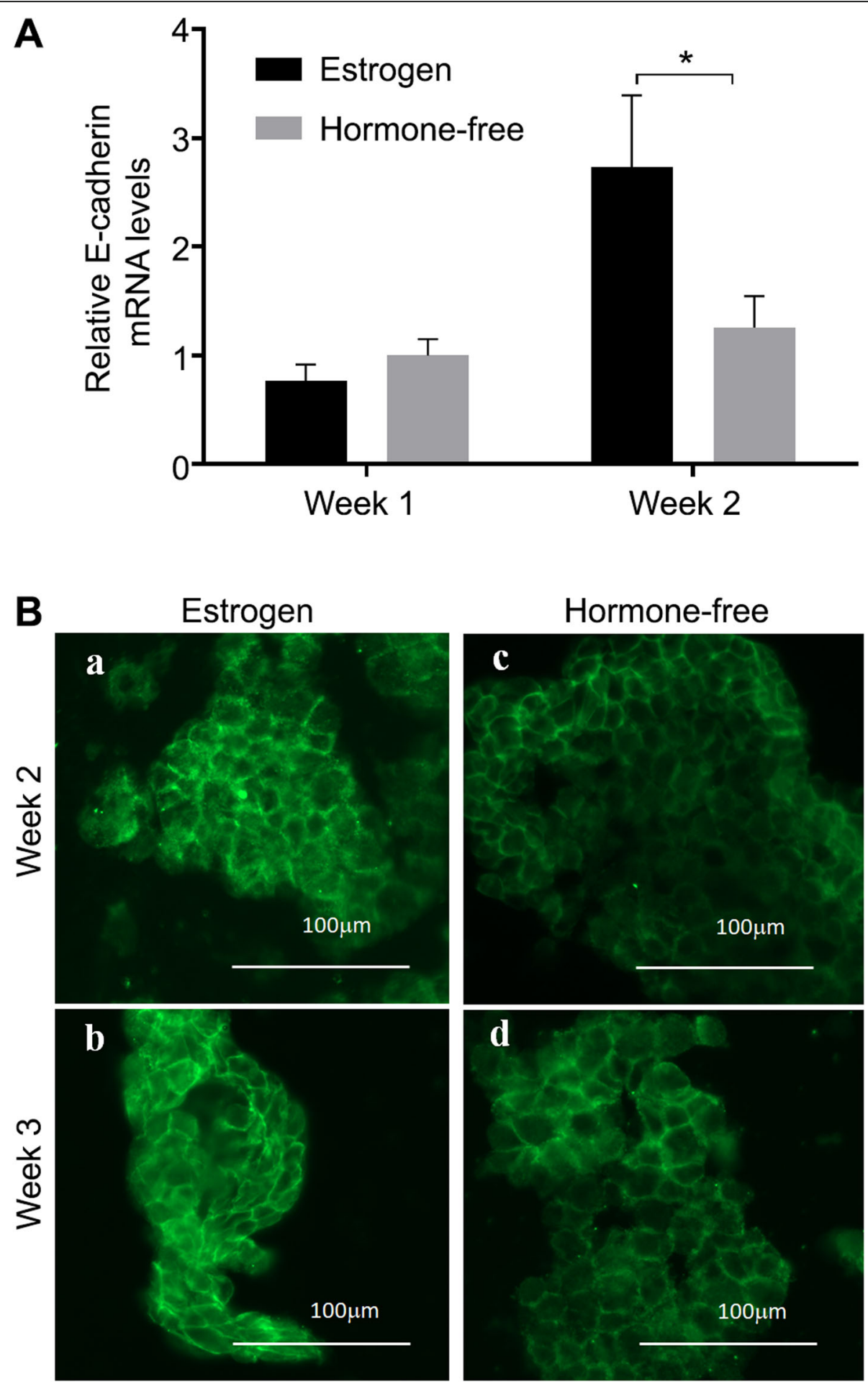

Fig. 3 E-cadherin expression in 3D RL95-2 epithelial model after 2 weeks of culture in estrogen-containing medium. A Quantification of Ecadherin mRNA expression levels evaluated by quantitative polymerase chain reaction (qPCR). mRNA expression levels were normalized to the ribosomal protein large PO (RPLP0) mRNA and to expression in 1-week old cell constructs in hormone-free medium $\left({ }^{*}\right.$ - $p<0.05,2$-way ANOVA, Bonferroni's post-hoc test, $n=8$ ). B Representative E-cadherin immunostaining of cryo-sections (10 $\mu \mathrm{m}$ thick) of RL95-2 endometrial cell constructs cultured in $(\mathbf{a}, \mathbf{b})$ estrogen-containing medium or in $(\mathbf{c}, \mathbf{d})$ hormone-free medium for $(\mathbf{a}, \mathbf{c}) 2$ weeks or (b, d) 3 weeks (Bar: $100 \mu \mathrm{m})$. 


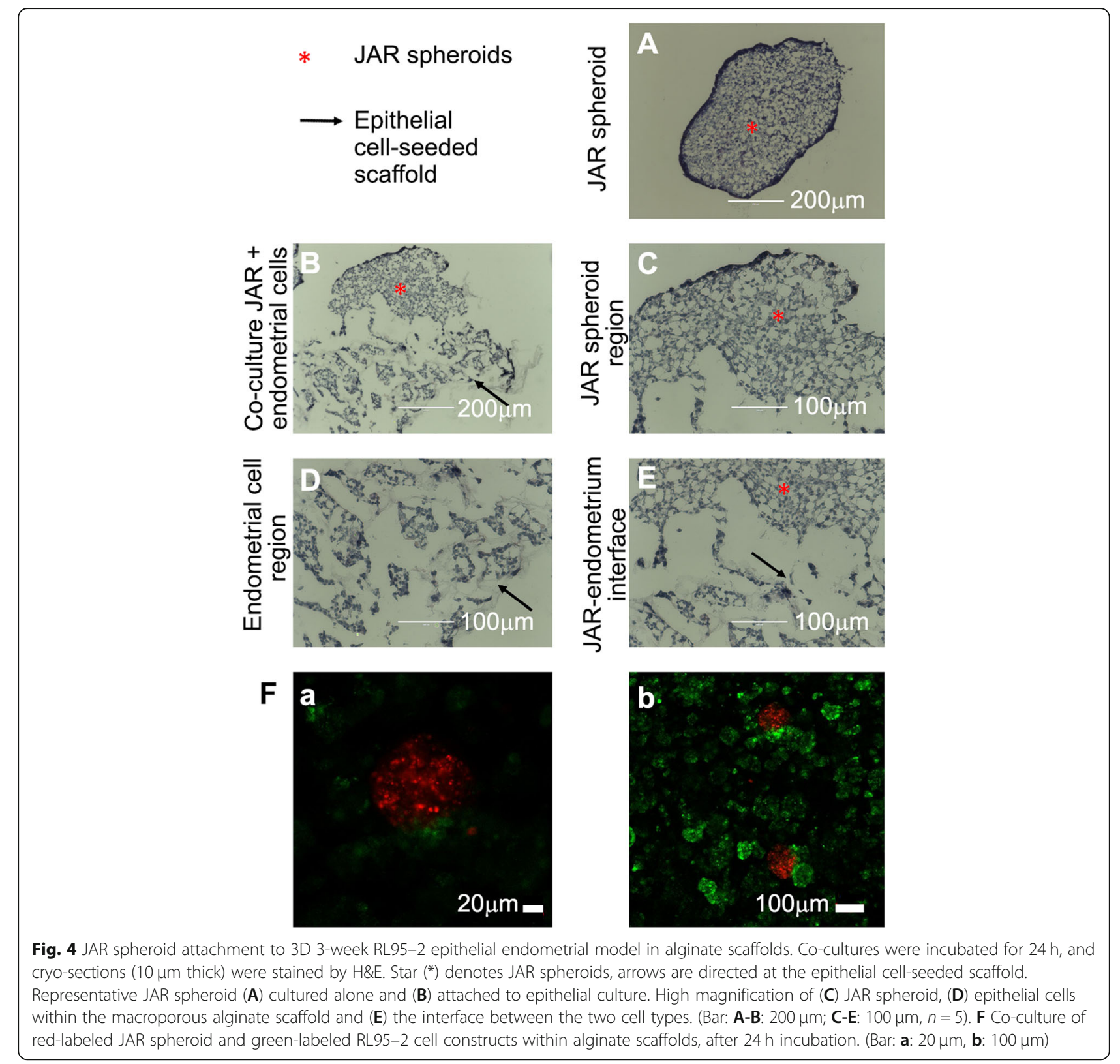

presence of the two cell types after $24 \mathrm{~h}$ of co-culture incubation (Fig. 4Fa and b).

\section{Restoring estrogen responsiveness in ERa-negative cells in the $3 \mathrm{D}$ endometrium-like model}

HEC-1A cells were used as a model for epithelial cells of RIF non-receptive endometrium. HEC-1A cells, known to express low levels of ER $\alpha$ [33], did not show any increase in E-cadherin expression in response to estrogen treatment (Fig. 5A). HEC-1A were transfected with fulllength ER $\alpha$ expressing plasmid. The stable transfection was confirmed by qPCR analysis that indicated elevated mRNA levels of ER $\alpha$ in the transfected cells, compared to cells transfected with an empty vector (Supplementary
Fig. $2 \mathrm{~A}, p<0.05)$. ER $\alpha$ was localized predominantly in the nuclei, as seen by specific immunofluorescent staining for ER $\alpha$ (Supplementary Fig. 2B).

Transfected cells were cultured within macroporous alginate scaffolds for 3 weeks under sequential hormonal treatment. These exhibited significantly higher Ecadherin mRNA expression levels compared to those of HEC-1A constructs (Fig. 5B, $p<0.05$ ). The expression levels of the transfected cells were slightly lower but not significantly different from those of RL95-2 cell constructs (Fig. 5B).

Immuno-staining for E-cadherin in the cell constructs revealed pronounced protein expression at cell boundaries of ER $\alpha$-transfected HEC-1A cells in comparison to 


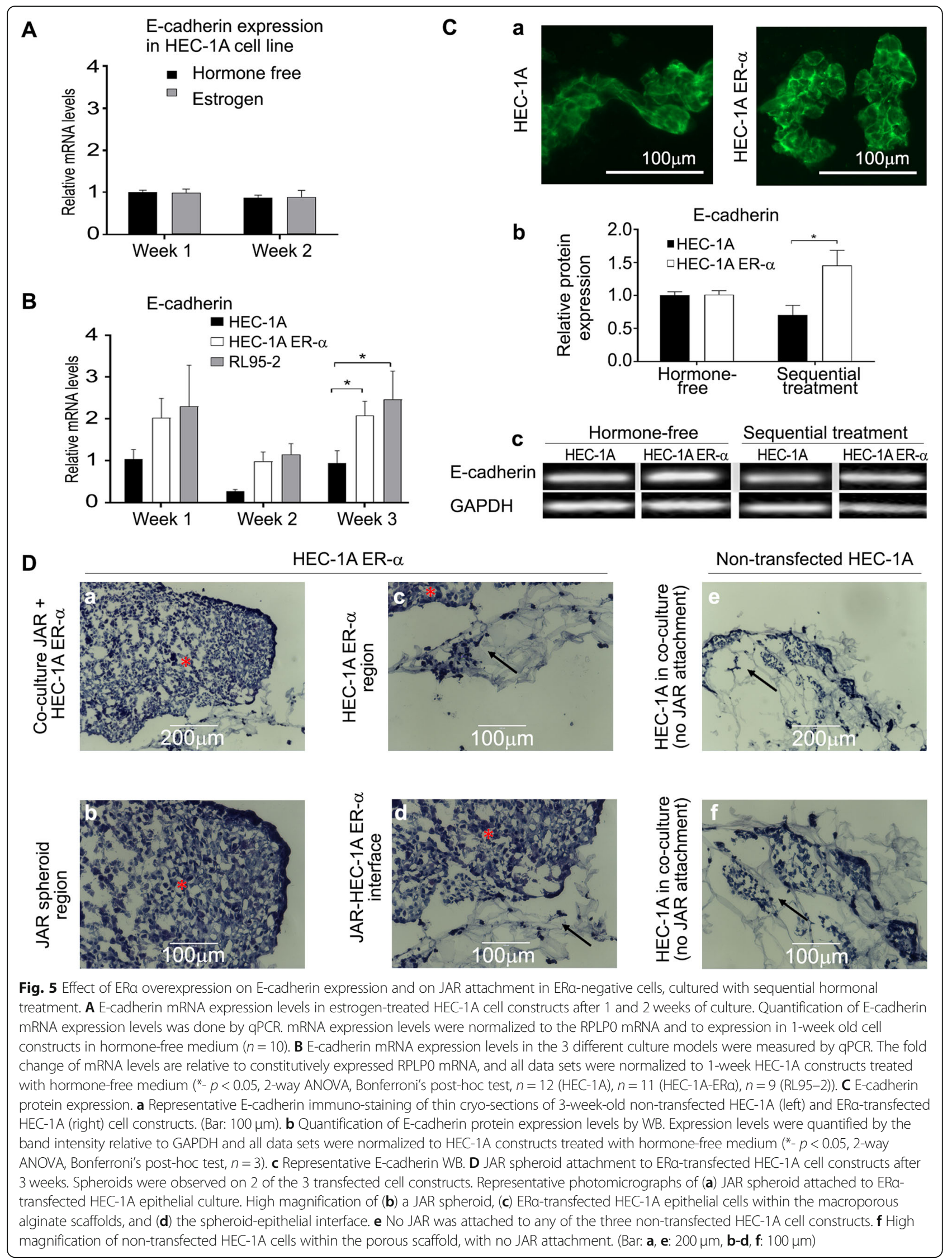


the non-transfected HEC-1A cells where slightly lower protein expression was observed (Fig. $5 \mathrm{Ca}$ ).

WB analysis indicated that E-cadherin protein expression levels in constructs of ER $\alpha$-transfected HEC-1A cells cultured with sequential hormonal treatment, were over two-fold higher after 2 weeks relative to nontransfected HEC-1A cells (Fig. 5Cb and c, $p<0.05$ ).

JAR spheroids were observed on 2 of 3 transfected cell constructs (Fig. 5Da-d). When non-transfected HEC-1A cell constructs were used, no JAR attachment was observed to any of the three HEC-1A cell constructs (Fig. 5 De-f), despite the cell population having the same gross morphology as in the RL95-2 cell constructs.

\section{Discussion}

This study presents a novel 3D model for epithelialembryo interactions in 3D macroporous alginate scaffolds. The endometrial epithelial cells that were cultured within the porous structure formed a tissue-like structure that was viable for 3 weeks under hormone treatment that mimicked the entire typical menstrual cycle. The newly-formed epithelial tissue-like construct of the receptive RL95-2 cell line was responsive to hormones, as judged from the hormone-dependent E-cadherin expression levels; and, most importantly, the RL95-2 cell constructs were functional in terms of their ability to adhere to JAR spheroids, mimicking the first step of implantation in fertile women.

A second 3D model was established that partially mimics the endometrium of RIF patients with nonreceptive endometrium tissue. To this end, HEC-1A epithelial cells, expressing low levels of ER $\alpha$ [33], were cultured within alginate scaffolds under the same conditions as the receptive RL95-2 constructs. The HEC-1A 3D model demonstrated lower levels of Ecadherin and JAR spheroids could not attach to the cell constructs, as opposed to the receptive RL95-2 3D model. ER $\alpha$ overexpression in HEC-1A cells restored Ecadherin expression both at the mRNA and protein levels. JAR spheroid attachment capability was also recovered in the ER $\alpha$-transfected cells, probably due to the enhanced adhesion mediated by E-cadherin, facilitating the cell-cell interactions with the embryo model [11]. Collectively, both models emphasize the importance of $E R \alpha$ and E-cadherin in the initial steps of embryo attachment and indicate a possible regulation mechanism of $\mathrm{E}$ cadherin by ER $\alpha[34,35]$.

The presented in vitro 3D models showed lower expression of E-cadherin in the RIF model of HEC-1A cells compared to the receptive RL95-2, in agreement with analyses of endometrium tissue of fertile women compared to that of RIF patients [6]. These clinical data together with the in vitro model results support previous reports demonstrating significantly lower levels of ER $\alpha$ and higher levels of the E-cadherin repressor, Slug transcription factor [36], in RIF endometrium [6].

The presented 3D RL95-2 model expressed ER $\alpha$, was responsive to hormones, expressed E-cadherin and enabled JAR attachment, making it a good in vitro model for fertile endometrium based on the clinical results presented here and previously [6]. The 3D HEC-1A model with lower levels of ER $\alpha$, expressed lower levels of Ecadherin and could not facilitate JAR attachment, making it an in vitro model for RIF endometrium.

The proposed novel 3D model based on macroporous alginate scaffolds represents a significant advantage in its ability to support a long-term viable culture of endometrial cells for several weeks under hormonal treatment, with observed hormone responsiveness and temporal tissue functionality, as demonstrated by JAR attachment. The 3D highly porous alginate scaffold, with interconnected pores, enabled extended viability presumably due to better mass transfer and accessibility to nutrients and hormones from the culture medium as well as to essential paracrine factors. The porous scaffold structure, with pore sizes of $\sim 80 \mu \mathrm{m}$, favors cell-cell and cell-matrix interactions with the secreted extracellular matrix (ECM), allowing better organization into tissue-like structures and functionality. Other 3D systems utilizing hydrogel networks are highly dense precluding efficient mass transfer, long-term viability and cell organization into tissue structure.

While alginate biomaterial simulates the hydrated structure of native ECM [37], it is cell-inert as no specific interactions are formed to the alginate scaffold [38]. This provides a means to examine cell organization without any biochemical effects of the biomaterial itself.

The developed in vitro 3D implantation model may serve as a platform for further studying the RIF endometrium and to ultimately increase endometrial receptivity. Such a model is of significant potential since the current evaluation of IVF treatment failure is mostly limited to analyzing the endometrium thickness [39].

Whereas this study addressed the initial step of blastocyst attachment to the epithelial cell layer, future studies using these models may utilize primary epithelial and stromal cells from the endometrium of RIF patients to examine individual failure mechanisms and to design therapies targeted at all stages of the embryo implantation process.

\section{Conclusions}

Taken together, the proposed novel 3D models of endometrium cells within macroporous alginate scaffolds enabled long-term culture of viable human endometrial cells under hormone stimulation that mimics the normal menstrual cycle. This model provides a platform for 
elaborate studies of the regulatory mechanisms involved in the implantation process and can set the basis for a broader tool for designing and testing novel therapeutic strategies for recurrent implantation failure.

\section{Materials and methods}

\section{RIF and fertile patients}

The clinical study was performed as previously described [6]. The study group consisted of patients under the age of 38 years with RIF, from the Hadassah University Hospital, IVF unit. Only patients who had undergone at least three IVF-embryo transfer failures, in which no less than 10 high quality embryos were transferred in total, were included. The control group of fertile women consisted of volunteer women under the age of 40 , who had at least one normal pregnancy and delivery. We excluded women who had a past record of infertility, those currently on oral contraceptive therapy and those with intrauterine contraceptive devices.

All patients had a good hormonal reserve $(\mathrm{FSH}<8$ $\mathrm{mIU} / \mathrm{mL}$ ) and a good response to hormonal stimulation (more than eight oocytes/oocyte retrieval). Patients were confirmed to have a normal uterine cavity by office hysteroscopy and normal endometrial thickness. Participants were instructed not to use hormone therapy during the research period.

All participants signed informed consent forms following the approval of the institutional ethics committee (number 14-11/10/02).

\section{Endometrial sampling}

Endometrial biopsies were collected using a Pipelle ${ }^{\circ}$ de Cornier device (CCD Laboratories, Paris, France) on day 10 and day 21 of the menstrual cycle, as previously described [6]. Endometrial samples of day 21 from patients and controls were confirmed to be postovulatory when serum progesterone level was above $20 \mathrm{ng} / \mathrm{mL}$. Samples were immediately transferred to the laboratory and processed within $1 \mathrm{~h}$.

\section{Macroporous alginate scaffold fabrication}

Alginate scaffolds with a diameter of $5 \mathrm{~mm}$ and $2 \mathrm{~mm}$ thickness were fabricated from low viscosity (LVG) alginate (LVG with MW $100 \mathrm{kDa},>65 \%$ guluronic acid monomer content, NovaMatrix FMC Biopolymers, Drammen, Norway) by a freeze-drying technique as previously described [29]. In short: Alginate was dissolved in double distilled water (DDW,1.2\% (w/v) solution) and then was cross-linked with calcium by adding a solution of D-gluconic acid hemicalcium salt $(1.2 \% \mathrm{w} / \mathrm{v})$ under homogenization for $2 \mathrm{~min}$. Final component concentrations in the cross-linked solution was 1.0 and $0.2 \%(\mathrm{w} / \mathrm{v})$ in DDW for the polymer and cross-linker, respectively. The cross-linked solution was poured into 96 -well plates
(100 $\mu \mathrm{L} /$ well), frozen at $-20^{\circ} \mathrm{C}$ for $24 \mathrm{~h}$ and then lyophilized. The scaffolds were sterilized by exposure to ultraviolet light in a biological hood for $1 \mathrm{~h}$.

Pore size in the scaffolds was measured by scanning electron microscope (SEM, Tescan, VEGA3) imaging of dry scaffolds.

\section{Cell construct preparation and cultivation}

RL95-2 (CRL-1671; American Type Culture Collection, Frederick, MD) was derived from a moderately differentiated adenosquamous carcinoma of the endometrium and was used as a model for receptive endometrium [7]. HEC-1A (HTB-112 American Type Culture Collection, Frederick, MD) was derived from human endometrial carcinoma and served as a model of the nonreceptive state [7]. The human choriocarcinoma cell line JAR (HTB-144 American Type Culture Collection, Frederick, $\mathrm{MD})$, cultured to form multicellular spheroids, was used as a model of blastocysts [7].

\section{Preparation for $3 D$ culture}

RL95-2 and JAR cells were grown in high-glucose Dulbecco's modified Eagle's medium (DMEM) and HEC-1A cells were cultured in McCoy's medium. Both media were supplemented with 10\% fetal calf serum (FCS), $1 \%$ penicillin-streptomycin-amphotericin solution, $1 \% \mathrm{~L}$ glutamine, $1 \%$ sodium pyruvate, $1 \%$ non-essential amino acids and $1 \%$ vitamins (all v/v). The medium was replaced twice a week until cells reached $80 \%$ confluence, at which stage they were seeded onto the scaffolds.

\section{$3 D$ culture}

Cell were seeded onto the scaffolds by applying $15 \mu \mathrm{L}$ of the cell suspension onto the dry scaffold $\left(3-5 \times 10^{5}\right.$ cells/scaffold) followed by centrifugation $(100 \times \mathrm{g}, 2 \mathrm{~min})$ and incubation for $0.5 \mathrm{~h}$ at $37{ }^{\circ} \mathrm{C}$ under $5 \% \mathrm{CO}_{2}$. Subsequently, seeded scaffolds were transferred to $750 \mu \mathrm{L}$ of culture medium at $37{ }^{\circ} \mathrm{C}$ under $5 \% \mathrm{CO}_{2}$. The regular menstrual cycle was modeled by cell constructs that were cultured for 3 weeks under sequential hormonal treatment of one-week estrogen priming $\left(10^{-8} \mathrm{M}\right)$, followed by 2 weeks of progesterone treatment $\left(10^{-7} \mathrm{M}\right)$, or in control media: (a) hormone-free, (b) estrogen $\left(10^{-8} \mathrm{M}\right)$. The medium was replaced twice a week.

\section{RNA isolation and quantitative polymerase chain reaction (qPCR)}

Cell constructs were incubated with $0.5 \mathrm{~mL}$ of TriReagent commercial kit (Sigma-Aldrich) according to the manufacturer's instructions. The extracted RNA was converted to cDNA with a qScript cDNA synthesis kit (Quanta Biosciences, Gaithersburg, MD). 
Oligonucleotide primers were designed by the Primer Express program (Applied Biosystems, Foster City, CA, USA) and were as follows:

E-cadherin: sense $5^{\prime}$-gccatcgcttacaccatcct- ${ }^{\prime}$, antisense $5^{\prime}$-ggcacctgaccttgtacgt- 3 '.

ER $\alpha$ : sense $5^{\prime}$-cggcattctacaggccaaa-3', antisense 5' gcgagtctccttggcagattc- 3 ' .

RPLP0 housekeeping gene [40]: sense $5^{\prime}$ -

ccaactacttccttaagatcatccaacta-3', antisense 5' acatgcggatctgctgca-3' .

qPCR was performed with a KAPA SYBRFAST Universal qPCR kit (Kapa Biosystems, Wilmington MA) on the CFX Connect Real-Time system (Bio-Rad Laboratories, Hercules CA). Analysis was performed with BioRad CFX Manager Software. Expression levels in each sample were normalized to RPLP0 levels.

\section{Western blotting (WB)}

Endometrial tissue samples as well as in vitro cells constructs were lysed in a lysis buffer (1\% NP40, $20 \mathrm{mM}$ Tris- $\mathrm{HCl}$ ( $\mathrm{pH} 7.5$ ), $137 \mathrm{mM} \mathrm{NaCl}, 0.5 \mathrm{mM}$ Ethylenediaminetetraacetic acid

Ethylenediaminetetraacetic acid (EDTA), 10\% glycerol, $1 \mathrm{mM}$ sodium orthovanadate, $1 \mathrm{X}$ protease inhibitors cocktail and $0.1 \%$ sodium dodecyl sulfate (SDS), (Sigma, St. Louis, MO, USA)). About $10 \mu \mathrm{g}$ of protein from each sample were loaded under reducing conditions on $10 \%$ SDS-polyacrylamide gels, separated by electrophoresis, transferred to polyvinylidene fluoride (PVDF) membranes. (Millipore, Bedford, MA, USA), blocked in Tris buffered saline with Tween 20 (TBST; $10 \mathrm{mM}$ Tris- $\mathrm{HCl}$ (pH 8.0), $150 \mathrm{mM} \mathrm{NaCl}$, and $0.1 \%$ Tween 20) containing $5 \%$ non-fat dry milk (Nestle, Vevey, Switzerland) for $1 \mathrm{~h}$ at room temperature. Blots were then incubated overnight at $4{ }^{\circ} \mathrm{C}$ with either (a) primary mouse antibody against human E-cadherin (HECD-1 clone, Alexis Biochemicals, Lausen, Switzerland) or (b) anti-tubulin antibody (Sigma), or (c) primary rabbit antibody against GAPDH (14C10, Cell Signaling, Danvers, MA); followed by $1 \mathrm{~h}$ incubation with anti-mouse or anti-rabbit HRPconjugated secondary antibodies, respectively (Jackson Immuno-Research Laboratories, Inc., West Grove, PA). Enhanced chemiluminescence (ECL) procedure was performed using an ECL-EZ kit (Biological Industries) with signal detection by Image-Lab (Bio-Rad Laboratories Ltd., UK). Protein bands were quantified using ImageJ software (NIH) and normalized to GAPDH expression levels.

\section{Histology and immunostaining}

Endometrial biopsy samples were embedded in paraffin for histological evaluation. Paraffin sections were immuno-stained for human E-cadherin with E-cadherin primary antibody.

In vitro cell constructs were embedded in optimal cutting temperature compound (OCT) (Sakura, NL) and were frozen at $-20{ }^{\circ} \mathrm{C}$ for $2 \mathrm{~h}$, then transferred to $80^{\circ} \mathrm{C}$ until sectioning. Frozen constructs were cut into $10 \mu \mathrm{m}$ thick sections by cryostat, mounted on slides, and stained for hematoxylin and eosin (H\&E). For immunofluorescence, the cryo-sections were dried at room temperature (RT) and dehydrated in DMEM-based buffer $\left(\mathrm{CaCl}_{2} \quad 2 \mathrm{H}_{2} \mathrm{O} \quad 0.265 \mathrm{~g} / \mathrm{L}, \mathrm{KCl} 0.400 \mathrm{~g} / \mathrm{L}, \mathrm{MgSO}_{4}\right.$ $7 \mathrm{H}_{2} \mathrm{O} \quad 0.200 \mathrm{~g} / \mathrm{L}, \mathrm{NaCl} 6.400 \mathrm{~g} / \mathrm{L}, \mathrm{NaHCO}_{3} 3.700 \mathrm{~g} / \mathrm{L}$, $\left.\mathrm{NaH}_{2} \mathrm{PO}_{4} 0.109 \mathrm{~g} / \mathrm{L}, \mathrm{pH} 7.2-7.4\right)$. Subsequently, sections were fixed in $4 \%$ neutral-buffered formalin for $10 \mathrm{~min}$ at $\mathrm{RT}$, washed and blocked for $1 \mathrm{~h}$ at RT in DMEM buffer containing 3\% BSA (w/v). Cryo-sections were incubated with E-cadherin primary antibody at $4{ }^{\circ} \mathrm{C}$ overnight and washed and incubated for $0.5 \mathrm{~h}$ with Alexa Fluor 488conjugated goat anti-mouse secondary antibody. Finally, the sections were washed and mounted on slides. Samples were examined by a Cytation ${ }^{\mathrm{TM}} 3$ microscope.

\section{JAR spheroid attachment to 3D endometrial model}

JAR trophoblast spheroids were prepared as indicated with some modifications [41]. Briefly, JAR cells were transferred to 6 -well plates $\left(2.5 \times 10^{5}\right.$ per well $)$ and agitated at $37{ }^{\circ} \mathrm{C}$ on a shaker for $24 \mathrm{~h}$. Then, the formed spheroids were collected and supernatant removed. A volume of $6 \mu \mathrm{L}$ of the suspended spheroids were seeded on top of 3-week old endometrial cell constructs within alginate scaffolds. The co-cultures were incubated for $24 \mathrm{~h}$ to allow spheroid attachment and then embedded in OCT and frozen. Cryo-sections of the co-culture were stained by $\mathrm{H} \& \mathrm{E}$.

\section{Fluorescent membranal staining}

For visualization of the two cell types, red and green fluorescent general membrane cell linkers were used: PKH26 red fluorescent staining for JAR spheroid and PKH67 green fluorescent staining for RL95-2 cellseeded scaffolds. Staining with PKH26 was done by incubating the JAR culture suspension with the dye as instructed by the manufacturer prior to spheroid formation. For PKH67, the provided manufacturer's protocol needed to be adapted for 3D culture. In brief, seeded scaffolds were first washed with serum-free medium (3 times), then incubated with PKH67 for $5 \mathrm{~min}$ and stopped with $1 \mathrm{~min}$ incubation with FCS, followed by 3 washing steps with culture medium. Immediately after staining, the red-labeled JAR spheroids were seeded onto the green-labeled RL95-2 3D cell constructs within the alginate scaffold, and the co-culture was incubated for $24 \mathrm{~h}$. The co-culture was visualized by confocal microscopy ZEISS LSM710. 


\section{Statistical analysis}

Statistical analysis was performed with GraphPad Prism, version 6.01 for Windows (GraphPad Software, San Diego, CA). All variables were expressed as mean \pm SEM.

E-cadherin protein expression of human samples were compared by 1 -way analysis of variance (ANOVA). Dunnett's post-hoc test was carried out to determine differences. E-cadherin mRNA and protein of in vitro models were compared by 2-way repeated measures ANOVA. Bonferroni's post-hoc test was carried out to determine differences. $p<0.05$ was considered to be statistically significant.

\section{Supplementary information}

Supplementary information accompanies this paper at https://doi.org/10. 1186/s13036-020-00240-7.

Additional file 1: Supplementary data 1. Presto blue $(\mathrm{PB})$ quantitative analysis of RL95-2 cell constructs. RL95-2 cell-seeded scaffolds were incubated for $2 \mathrm{~h}$ with $10 \%$ (v/v) PB reagent (in DMEM medium, supplemented with $10 \%(\mathrm{v} / \mathrm{v})$ FCS). Then samples of $100 \mu \mathrm{L}$ of the medium were transferred to a black bottom 96-well plate and fluorescent readings were obtained at excitation and emission wavelengths of $560 \mathrm{~nm}$ and $590 \mathrm{~nm}$, respectively. A calibration curve was prepared to quantify viable cells. Cell numbers at each time point were calculated by using a calibration curve and were normalized to the number of cells seeded into the scaffolds. Supplementary Fig. 1. (A) RL95-2 cell viability after 1- and 2weeks culture, by PB analysis. PB analysis of scaffolds, seeded with $0.5 \times 10^{6}$ cells showed no significant decrease throughout 2 weeks culture (B) Analysis of scaffolds, seeded with $6.25 \times 10^{4}$ cells, one order of magnitude less than $A$, showed a steady cell number after 1 week of culture and a significant increase after 2 weeks of culture.

Additional file 2: Supplementary data 2. ERa transfection of HEC-1A cells. The ERa open reading frame was cloned into a pcDNA6.2N5 vector (a kind gift from Prof. Carlos Simon, University of Valencia). HEC-1A cells were transfected using Lipofectamine ${ }^{\mathrm{TM}} 2000$ (Invitrogen, Paisley, UK) either with the ERa vector or with an empty vector as control. Following $48 \mathrm{~h}$, medium was replaced with $10 \mu \mathrm{g} / \mathrm{mL}$ blasticidin-containing media (Invitrogen, Paisley, UK) for selection. After 2 weeks, individual colonies were selected. Transfection efficiency was confirmed by ERa mRNA expression levels, evaluated by qPCR and ERa nuclear localization, and evaluated by immunofluorescent staining. Supplementary Fig. 2. Validation of ERa transfection evaluated by ERa expression in ERa transfected HEC1 A cells compared to HEC-1A cells transfected with the empty vector. (A) qPCR analysis: Higher ERa mRNA expression levels in ERa transfected HEC-1A cells, compared to cells transfected with an empty vector (t-test, $p<0.01$ ). Expression levels are relative to RPLPO levels. (B) Anti-ERa immunofluorescent staining: ERa protein expression in ERa transfected HEC-1A cells (right), compared to cells transfected with an empty vector (left). ERa immunofluorescent staining (green) and 4',6-diamidino-2-phenylindole (DAPI) staining for nuclei (blue) (Bar: $100 \mu \mathrm{m})$.

\section{Abbreviations}

ANOVA: Analysis of variance; DDW: Double distilled water; DMEM: Dulbecco's modified Eagle's medium; ECL: Enhanced chemiluminescence; EDTA: Ethylenediaminetetraacetic acid; ERa: Estrogen receptor alpha; FCS: Fetal calf serum; GAPDH: Glyceraldehyde 3-phosphate dehydrogenase; H\&E: Hematoxylin and Eosin; OCT: Optimal cutting temperature; PB: Presto blue; qPCR: Quantitative polymerase chain reaction; RIF: Recurrent implantation failure; RPLPO: Ribosomal protein lateral stalk subunit PO; RT: Room temperature; SDS: Sodium dodecyl sulfate; TBST: Tris buffered saline with Tween 20; WB: Western blot; WOI: Window of implantation

\section{Acknowledgments}

The authors thank Deborah E. Shalev for her generous assistance in manuscript preparation and editing.

\section{Authors' contributions}

DST performed all in vitro studies, the relevant analyses and was a major contributor in writing the manuscript. All authors read and approved the final manuscript. HA was responsible for the analysis of endometrium tissue and for HEC-1A cell transfection. LC was responsible for the analysis of Presto blue assay and JAR spheroid attachment assay, performed with membranal fluorescent staining. TTR and RR designed the studies, supervised the experiments and wrote the manuscript.

\section{Funding}

The research was partially supported by the Azrieli College of Engineering Jerusalem Research Fund.

Availability of data and materials

The datasets during and/or analyzed during the current study available from the corresponding author on reasonable request.

Ethics approval and consent to participate

All participants signed informed consent forms following the approval of the institutional ethics committee (number 14-11/10/02).

\section{Consent for publication}

Not applicable.

\section{Competing interests}

The authors declare that they have no competing interests.

Received: 8 March 2020 Accepted: 22 May 2020

Published online: 30 June 2020

\section{References}

1. Koot YE, Teklenburg G, Salker MS, Brosens JJ, Macklon NS. Molecular aspects of implantation failure. Biochim Biophys Acta. 2012;1822(12):1943-50.

2. Sharkey AM, Macklon NS. The science of implantation emerges blinking into the light. Reprod BioMed Online. 2013;27(5):453-60.

3. Weimar $\mathrm{CH}$, Post Uiterweer ED, Teklenburg G, Heijnen CJ, Macklon NS. Invitro model systems for the study of human embryo-endometrium interactions. Reprod BioMed Online. 2013;27(5):461-76.

4. Coughlan C, Ledger W, Wang Q, Liu F, Demirol A, Gurgan T, et al. Recurrent implantation failure: definition and management. Reprod BioMed Online. 2014;28(1):14-38.

5. Guzeloglu-Kayisli O, Kayisli UA, Taylor HS. The role of growth factors and cytokines during implantation: endocrine and paracrine interactions. Semin Reprod Med. 2009;27(1):62-79.

6. Koler M, Achache H, Tsafrir A, Smith Y, Revel A, Reich R. Disrupted gene pattern in patients with repeated in vitro fertilization (IVF) failure. Hum Reprod. 2009;24(10):2541-8.

7. John NJ, Linke M, Denker HW. Quantitation of human choriocarcinoma spheroid attachment to uterine epithelial cell monolayers. In Vitro Cell Dev Biol Anim. 1993;29(6):461-8.

8. Young SL. Oestrogen and progesterone action on endometrium: a translational approach to understanding endometrial receptivity. Reprod BioMed Online. 2013;27(5):497-505.

9. Gou J, Hu T, Li L, Xue L, Zhao X, Yi T, et al. Role of epithelial-mesenchymal transition regulated by twist basic helix-loop-helix transcription factor 2 (Twist2) in embryo implantation in mice. Reprod Fertil Dev. 2019;31(5):93240.

10. Zhang D, Lv P, Zhang R, Luo Q, Ding G, Yin L, et al. A new model for embryo implantation: coculture of blastocysts and Ishikawa cells. Gynecol Endocrinol. 2012:28(4):288-92.

11. Rahnama F, Thompson B, Steiner M, Shafiei F, Lobie PE, Mitchell MD. Epigenetic regulation of E-cadherin controls endometrial receptivity. Endocrinology. 2009;150(3):1466-72.

12. Singh $H$, Nardo L, Kimber SJ, Aplin JD. Early stages of implantation as revealed by an in vitro model. Reproduction. 2010;139(5):905-14. 
13. Evans J, Walker KJ, Bilandzic M, Kinnear S, Salamonsen LA. A novel "embryoendometrial" adhesion model can potentially predict "receptive" or "nonreceptive" endometrium. J Assist Reprod Genet. 2020;37(1):5-16.

14. You Y, Stelzl P, Zhang Y, Porter J, Liu H, Liao AH, et al. Novel 3D in vitro models to evaluate trophoblast migration and invasion. Am J Reprod Immunol. 2019:81(3):e13076.

15. Berneau SC, Ruane PT, Brison DR, Kimber SJ, Westwood M, Aplin JD. Characterisation of osteopontin in an in vitro model of embryo implantation. Cells. 2019;8(5):432.

16. Gnecco JS, Pensabene V, Li DJ, Ding T, Hui EE, Bruner-Tran KL, et al. Compartmentalized culture of perivascular Stroma and endothelial cells in a microfluidic model of the human endometrium. Ann Biomed Eng. 2017; 45(7):1758-69.

17. Arnold JT, Kaufman DG, Seppala M, Lessey BA. Endometrial stromal cells regulate epithelial cell growth in vitro: a new co-culture model. Hum Reprod. 2001;16(5):836-45.

18. Kim MR, Park DW, Lee JH, Choi DS, Hwang KJ, Ryu HS, et al. Progesteronedependent release of transforming growth factor-beta1 from epithelial cells enhances the endometrial decidualization by turning on the Smad signalling in stromal cells. Mol Hum Reprod. 2005;11(11):801-8.

19. Wang H, Pilla F, Anderson S, Martinez-Escribano S, Herrer I, Moreno-Moya $J M$, et al. A novel model of human implantation: 3D endometrium-like culture system to study attachment of human trophoblast (Jar) cell spheroids. Mol Hum Reprod. 2012;18(1):33-43.

20. Wang H, Bocca S, Anderson S, Yu L, Rhavi BS, Horcajadas J, et al. Sex steroids regulate epithelial-stromal cell cross talk and trophoblast attachment invasion in a three-dimensional human endometrial culture system. Tissue Eng Part C Methods. 2013;19(9):676-87.

21. Zambuto SG, Clancy KBH, Harley BAC. A gelatin hydrogel to study endometrial angiogenesis and trophoblast invasion. Interface Focus. 2019; 9(5):20190016

22. Dvir-Ginzberg M, Elkayam T, Cohen S. Induced differentiation and maturation of newborn liver cells into functional hepatic tissue in macroporous alginate scaffolds. FASEB J. 2008;22(5):1440-9.

23. Chen CY, Ke CJ, Yen KC, Hsieh HC, Sun JS, Lin FH. 3D porous calciumalginate scaffolds cell culture system improved human osteoblast cell clusters for cell therapy. Theranostics. 2015;5(6):643-55.

24. Gerecht-Nir S, Cohen S, Ziskind A, Itskovitz-Eldor J. Three-dimensional porous alginate scaffolds provide a conducive environment for generation of well-vascularized embryoid bodies from human embryonic stem cells. Biotechnol Bioeng. 2004;88(3):313-20.

25. Dvir-Ginzberg M, Gamlieli-Bonshtein I, Agbaria R, Cohen S. Liver tissue engineering within alginate scaffolds: effects of cell-seeding density on hepatocyte viability, morphology, and function. Tissue Eng. 2003;9(4):75766.

26. Re'em T, Kaminer-Israeli Y, Ruvinov E, Cohen S. Chondrogenesis of hMSC in affinity-bound TGF-beta scaffolds. Biomaterials. 2012;33(3):751-61.

27. Lei L, Li X, Xiong T, Yu J, Yu X, Song Z, et al. Covalently cross-linked chitosan hydrogel sheet for topical ophthalmic delivery of levofloxacin. J Biomed Nanotechnol. 2018;14(2):371-8.

28. Liu Y, Yao Q, Sun H. Prostaglandin E2 modulates bone morphogenetic Protein-2 induced Osteogenic differentiation on a biomimetic 3D Nanofibrous scaffold. J Biomed Nanotechnol. 2018;14(4):747-55.

29. Shapiro L, Cohen S. Novel alginate sponges for cell culture and transplantation. Biomaterials. 1997;18(8):583-90.

30. Zmora S, Glicklis R, Cohen S. Tailoring the pore architecture in 3-D alginate scaffolds by controlling the freezing regime during fabrication. Biomaterials. 2002;23(20):4087-94

31. Glicklis R, Shapiro L, Agbaria R, Merchuk JC, Cohen S. Hepatocyte behavior within three-dimensional porous alginate scaffolds. Biotechnol Bioeng. 2000; 67(3):344-53.

32. Re'em T, Tsur-Gang O, Cohen S. The effect of immobilized RGD peptide in macroporous alginate scaffolds on TGFbeta1-induced chondrogenesis of human mesenchymal stem cells. Biomaterials. 2010;31(26):6746-55.

33. Hevir-Kene N, Rizner TL. The endometrial cancer cell lines Ishikawa and HEC-1A, and the control cell line HIEEC, differ in expression of estrogen biosynthetic and metabolic genes, and in androstenedione and estronesulfate metabolism. Chem Biol Interact. 2015;234:309-19.

34. Ye Y, Xiao Y, Wang W, Yearsley K, Gao JX, Shetuni B, et al. ERalpha signaling through slug regulates E-cadherin and EMT. Oncogene. 2010;29(10):145162.
35. Fearon ER. Connecting estrogen receptor function, transcriptional repression, and E-cadherin expression in breast cancer. Cancer Cell. 2003; 3(4):307-10.

36. Bolos V, Peinado H, Perez-Moreno MA, Fraga MF, Esteller M, Cano A. The transcription factor slug represses E-cadherin expression and induces epithelial to mesenchymal transitions: a comparison with snail and E47 repressors. J Cell Sci. 2003;116(Pt 3):499-511.

37. Antoni $D$, Burckel $H$, Josset E, Noel G. Three-dimensional cell culture: a breakthrough in vivo. Int J Mol Sci. 2015;16(3):5517-27.

38. Lee KY, Mooney DJ. Alginate: properties and biomedical applications. Prog Polym Sci. 2012;37(1):106-26.

39. von Wolff M, Fah M, Roumet M, Mitter $V$, Stute $P$, Griesinger $G$, et al. Thin Endometrium Is Also Associated With Lower Clinical Pregnancy Rate in Unstimulated Menstrual Cycles: A Study Based on Natural Cycle IVF. Front Endocrinol (Lausanne). 2018;9:776.

40. Lossos IS, Czerwinski DK, Wechser MA, Levy R. Optimization of quantitative real-time RT-PCR parameters for the study of lymphoid malignancies. Leukemia. 2003;17(4):789-95.

41. John NJ, Linke M, Denker HW. Quantitation of human choriocarcinoma speroid attachment to uterine epithelial cell monolayers. In Vitro Cell Dev Biol. 1993;29A:461-8.

\section{Publisher's Note}

Springer Nature remains neutral with regard to jurisdictional claims in published maps and institutional affiliations.
Ready to submit your research? Choose BMC and benefit from:

- fast, convenient online submission

- thorough peer review by experienced researchers in your field

- rapid publication on acceptance

- support for research data, including large and complex data types

- gold Open Access which fosters wider collaboration and increased citations

- maximum visibility for your research: over $100 \mathrm{M}$ website views per year

At BMC, research is always in progress.

Learn more biomedcentral.com/submissions 